\title{
The worldwide leaf economics spectrum
}

\author{
Ian J. Wright ${ }^{1}$, Peter B. Reich ${ }^{2}$, Mark Westoby ${ }^{1}$, David D. Ackerly ${ }^{3}$, Zdravko Baruch ${ }^{4}$, Frans Bongers ${ }^{5}$, Jeannine Gavender-Bares ${ }^{6}$, \\ Terry Chapin ${ }^{7}$, Johannes H. C. Cornelissen ${ }^{8}$, Matthias Diemer ${ }^{9}$, Jaume Flexas ${ }^{10}$, Eric Garnier ${ }^{11}$, Philip K. Groom ${ }^{12}$, Javier Gulias ${ }^{10}$, \\ Kouki Hikosaka ${ }^{13}$, Byron B. Lamont ${ }^{12}$, Tali Lee $^{14}$, William Lee ${ }^{15}$, Christopher Lusk ${ }^{16}$, Jeremy J. Midgley ${ }^{17}$, Marie-Laure Navas ${ }^{11}$, \\ Ülo Niinemets ${ }^{18}$, Jacek Oleksyn ${ }^{2,19}$, Noriyuki Osada ${ }^{20}$, Hendrik Poorter ${ }^{21}$, Pieter Poot ${ }^{22}$, Lynda Prior ${ }^{23}$, Vladimir I. Pyankov ${ }^{24}$, \\ Catherine Roumet $^{11}$, Sean C. Thomas ${ }^{25}$, Mark G. Tjoelker ${ }^{26}$, Erik J. Veneklaas ${ }^{22}$ \& Rafael Villar ${ }^{27}$ \\ ${ }^{1}$ Department of Biological Sciences, Macquarie University, New South Wales 2109, Australia \\ ${ }^{2}$ Department of Forest Resources, University of Minnesota, St Paul, Minnesota 55108, USA \\ ${ }^{3}$ Department of Biological Sciences, Stanford University, Stanford, California 94305, USA \\ ${ }^{4}$ Departamento de Estudios Ambientales, Universidad Simón Bolivar, Caracas 1080, Venezuela \\ ${ }^{5}$ Forest Ecology and Forest Management Group, Department of Environmental Sciences, Wageningen University, PO Box 342 , 6700 AH Wageningen, \\ The Netherlands \\ ${ }^{6}$ Smithsonian Environmental Research Center, PO Box 28, 647 Contees Wharf Road, Edgewater, Maryland 21037, USA \\ ${ }^{7}$ Institute of Arctic Biology, University of Alaska, Fairbanks, Alaska 99775, USA \\ ${ }^{8}$ Institute of Ecological Science, Department of Systems Ecology, Vrije Universiteit, De Boelelaan 1087, 1081 HV, Amsterdam, The Netherlands \\ ${ }^{9}$ Institute für Umweltwissensch, University of Zurich, Zurich, Switzerland \\ ${ }^{10}$ Departament de Biologia, Laboratori de Fisiologia Vegetal, Universidad de Illes Balears, 07122 Palma de Mallorca, Illes Balears (Spain) \\ ${ }^{11}$ Centre d'Ecologie Fonctionnelle et Evolutive, CNRS, UMR 5175, 1919, Route de Mende, 34293 Montpellier cedex 5, France \\ ${ }^{12}$ Department of Environmental Biology, Curtin University of Technology, Perth, Western Australia 6845, Australia \\ ${ }^{13}$ Graduate School of Life Sciences, Tohoku University, Aoba, Sendai 980-8578, Japan \\ ${ }^{14}$ Department of Biology, University of Wisconsin-Eau Claire, Eau Claire, Wisconsin 54702-4004, USA \\ ${ }^{15}$ Landcare Research, Private Bag 1930, Dunedin, New Zealand \\ ${ }^{16}$ Departamento de Botánica, Universidad de Concepción, Casilla 160-C, Concepción, Chile \\ ${ }^{17}$ Department of Botany, University of Cape Town, ZA-7701 Rondebosch, South Africa \\ ${ }^{18}$ Department of Plant Physiology, University of Tartu, Riia 23, Tartu 51011, Estonia \\ ${ }^{19}$ Polish Academy of Sciences, Institute of Dendrology, Parkowa 5, 62-035 Kornik, Poland \\ ${ }^{20}$ Nikko Botanical Garden, Graduate School of Science, University of Tokyo, 1842 Hanaishi, Nikko, Tochigi 321-1435, Japan \\ ${ }^{21}$ Plant Ecophysiology, Utrecht University, PO Box 800.84, 3508 TB, Utrecht, The Netherlands \\ ${ }^{22}$ School of Plant Biology, University of Western Australia, Crawley, Western Australia 6009, Australia \\ ${ }^{23}$ Key Centre for Tropical Wildlife Management, Charles Darwin University, Darwin, Northern Territory 0909, Australia \\ ${ }^{24}$ Ural State University, Yekaterinburg, Russia \\ ${ }^{25}$ Faculty of Forestry, University of Toronto, 33 Willcocks St, Toronto, Ontario M5S 3B3, Canada \\ ${ }^{26}$ Department of Forest Science, Texas A\&M University, 2135 TAMU, College Station, Texas 77843-2135, USA \\ ${ }^{27}$ Area de Ecología, Campus de Rabanales, Universidad de Córdoba, 14071 Córdoba, Spain
}

Bringing together leaf trait data spanning 2,548 species and 175 sites we describe, for the first time at global scale, a universal spectrum of leaf economics consisting of key chemical, structural and physiological properties. The spectrum runs from quick to slow return on investments of nutrients and dry mass in leaves, and operates largely independently of growth form, plant functional type or biome. Categories along the spectrum would, in general, describe leaf economic variation at the global scale better than plant functional types, because functional types overlap substantially in their leaf traits. Overall, modulation of leaf traits and trait relationships by climate is surprisingly modest, although some striking and significant patterns can be seen. Reliable quantification of the leaf economics spectrum and its interaction with climate will prove valuable for modelling nutrient fluxes and vegetation boundaries under changing land-use and climate.

Green leaves are fundamental for the functioning of terrestrial ecosystems. Their pigments are the predominant signal seen from space. Nitrogen uptake and carbon assimilation by plants and the decomposability of leaves drive biogeochemical cycles. Animals, fungi and other heterotrophs in ecosystems are fuelled by photosynthate, and their habitats are structured by the stems on which leaves are deployed. Plants invest photosynthate and mineral nutrients in the construction of leaves, which in turn return a revenue stream of photosynthate over their lifetimes. The photosynthate is used to acquire mineral nutrients, to support metabolism and to re-invest in leaves, their supporting stems and other plant parts.

There are more than 250,000 vascular plant species, all engaging in the same processes of investment and reinvestment of carbon and mineral nutrients, and all making enough surplus to ensure continuity to future generations. These processes of investment and re-investment are inherently economic in nature ${ }^{1-3}$. Understanding how these processes vary between species, plant functional types and the vegetation of different biomes is a major goal for plant ecology and crucial for modelling how nutrient fluxes and vegetation boundaries will shift with land-use and climate change.

\section{Data set and parameters}

We formed a global plant trait network (Glopnet) to quantify leaf economics across the world's plant species. The Glopnet data set spans 2,548 species from 219 families at 175 sites (approximately $1 \%$ of the extant vascular plant species). The coverage of traits, species and sites is at least tenfold greater than previous data compilations $^{4-11}$, extends to all vegetated continents, and represents a wide range of vegetation types, from arctic tundra to tropical rainforest, from hot to cold deserts, from boreal forest to grasslands. Site elevation ranges from below sea level (Death Valley, USA) to $4,800 \mathrm{~m}$. Mean annual temperature (MAT) ranges from $-16.5^{\circ} \mathrm{C}$ to $27.5^{\circ} \mathrm{C}$; mean annual rainfall (MAR) ranges from 133 to $5,300 \mathrm{~mm}$ per year. This covers most of the range of MAT-MAR space in which higher plants occur ${ }^{12}$ (Fig. 1). The broad coverage of the data set has 
allowed us to quantify the relationships of leaf economics to climate at a scale not previously possible. Here we report some global outcomes from our analyses.

We focus on six key features of leaves that together capture many essentials of leaf economics. (1) Leaf mass per area (LMA) measures the leaf dry-mass investment per unit of light-intercepting leaf area deployed. Species with high LMA have a thicker leaf blade or denser tissue, or both. (2) Photosynthetic assimilation rates measured under high light, ample soil moisture and ambient $\mathrm{CO}_{2}$ are here called photosynthetic capacity $\left(A_{\text {mass }}\right)$ for brevity. Photosynthetic capacity is influenced both by stomatal conductance and by the drawdown of $\mathrm{CO}_{2}$ concentration inside the leaf (carboxylation capacity). (3) Leaf nitrogen $(\mathrm{N})$ is integral to the proteins of photosynthetic machinery, especially Rubisco ${ }^{8,13}$. The photosynthetic machinery is responsible for drawdown of $\mathrm{CO}_{2}$ inside the leaf, a process also affected by leaf structure ${ }^{14,15}$. (4) Leaf phosphorus (P) is found in nucleic acids, lipid membranes and bioenergetic molecules such as ATP. Phosphorus derives from weathering of soil minerals at a site, in contrast to nitrogen, much of which may be fixed from the atmosphere by plants. (5) Dark respiration rate $\left(R_{\text {mass }}\right)$ reflects metabolic expenditure of photosynthate in the leaf, especially protein turnover and phloem-loading of photosynthates ${ }^{16}$. (6) Leaf lifespan (LL) describes the average duration of the revenue stream from each leaf constructed. Long LL requires

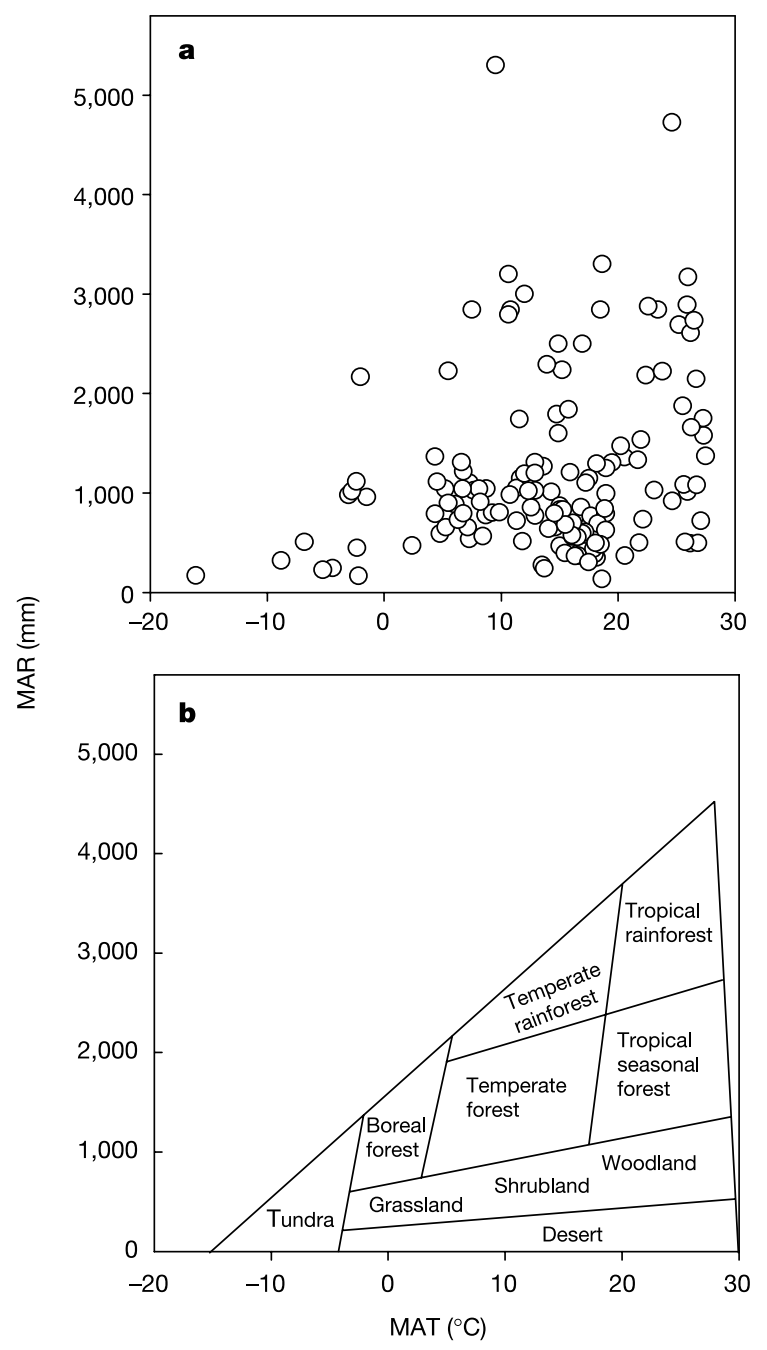

Figure 1 Mean annual rainfall (MAR) and mean annual temperature (MAT). Results for the 175 sites from where leaf data were compiled (a), in relation to major biome types of the world (b), following ref. 12. Biome boundaries are only approximate.
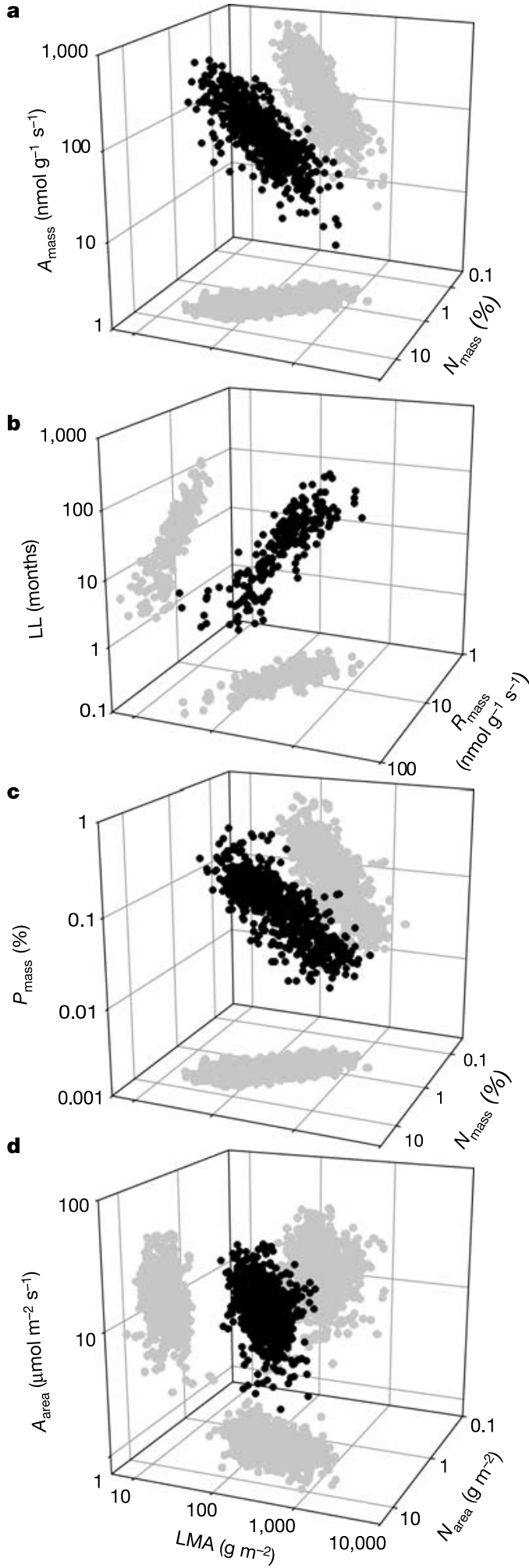

Figure 2 Three-way trait relationships among the six leaf traits with reference to LMA, one of the key traits in the leaf economics spectrum. The direction of the data cloud in three-dimensional space can be ascertained from the shadows projected on the floor and walls of the three-dimensional space. Sample sizes for three-way relationships are necessarily a subset of those for each of the bivariate relationships. a, $A_{\text {mass, }}$ LMA and $N_{\text {mass; }} ; 06$ species. b, LL, $R_{\text {mass }}$ and LMA; 217 species. c, $N_{\text {mass }}, P_{\text {mass }}$ and LMA; 733 species. $\mathbf{d}, A_{\text {area }}, \mathrm{LMA}$ and $N_{\text {area }} ; 706$ species. 
robust construction in the form of high $\mathrm{LMA}^{6,17,18}$.

Ecophysiological attributes such as leaf $\mathrm{N}$, leaf $\mathrm{P}, A_{\text {mass }}$ or $R_{\text {mass }}$ can be expressed per leaf area, per leaf dry mass or per leaf volume. A leaf-area basis reflects fluxes in relation to surfaces. It is a natural basis for describing light capture and for expressing transactions through surfaces such as trade-offs between carbon gain and water transpiration ${ }^{19,20}$. On a mass basis, leaf economics are quantified in terms of revenues and expenditures per unit investment, measured as biomass, or $\mathrm{C}, \mathrm{N}$ or P. Scaling up to whole plants, mass-based expressions of leaf nutrient concentrations $\left(N_{\text {mass }}, P_{\text {mass }}\right), A_{\text {mass }}$ and $R_{\text {mass }}$ are more tightly correlated than area-based expressions to relative growth rates of seedlings or to absolute height growth rates of young trees ${ }^{21,22}$. By definition, area- and mass-based traits can be interconverted via LMA (for example, $N_{\text {area }}=N_{\text {mass }} \times$ LMA). Here we report relationships among leaf traits using both area- and massbased formulations, and also analyses where the effect of LMA is explicitly controlled.

We first quantify relationships among the six mass-based leaf traits: $\mathrm{A}_{\text {mass }}, R_{\text {mass }}$, LMA, LL, $N_{\text {mass }}$ and $P_{\text {mass }}$. We find that these economic traits covary tightly across all species. Trait relationships are similar for species pooled by growth form, plant functional group or biome, which indicates the existence of a single global spectrum of leaf economic variation. Second, we treat photosynthetic capacity, $R_{\text {mass }}$ and leaf nutrient concentrations on a leaf-area basis. These relationships are not as strong as among mass-basis traits, and we consider why. Third, we assess the influence of climate on leaf trait relationships. We find that, in general, the influence is modest, although particular traits and trait relationships show substantial patterning with climate.

\section{The leaf economics spectrum}

\section{Mass-based leaf traits}

The six mass-basis leaf traits varied by one to two orders of magnitude across the data set. LMA ranged from 14 to $1,500 \mathrm{~g} \mathrm{~m}^{-2}$ and LL from 0.9 up to 288 months. $A_{\text {mass }}$ ranged from 5 to $660 \mathrm{nmolg}^{-1} \mathrm{~s}^{-1}$; dark respiration from 2.2 to $65 \mathrm{nmolg}^{-1} \mathrm{~s}^{-1}$. $N_{\text {mass }}$ ranged from 0.2 to $6.4 \%$; $P_{\text {mass }}$ from 0.008 to $0.6 \%$. Considered pairwise, all leaf traits were highly correlated (Table 1). These correlations have been reported previously from smaller data sets $^{6-10,23}$. Here we have generalized the patterns over many more species, sites and vegetation types.

We moved beyond pairwise consideration of traits to determine the extent to which leaf economic traits covary in multidimensional trait space. This covariation can be quantified as the proportion of total trait variation explained by the first principal axis in a principal components analysis. In two-trait space, the principal axis is the long axis of the ellipse resulting from two correlated traits. In threetrait space, the principal axis is the long axis of an ellipsoid. In multidimensional trait space, the principal axis describes the main axis of variation through a hyperellipsoid ${ }^{24}$. A remarkable $82 \%$ of all variation in $A_{\text {mass }}$, LMA and $N_{\text {mass }}$ across species lay along the first principal axis in three-trait space (Fig. 2a). Because some of the residual $18 \%$ must be measurement variation, $82 \%$ represents a minimum estimate of the dominance of this single spectrum in explaining variation across plant species worldwide. Further three- dimensional subsets of the six-dimensional data set are shown in Figs $2 \mathrm{~b}$ and $\mathrm{c}$. Multi-dimensional analyses including from four to all six of the traits similarly showed the large majority of variation explained with a single axis (Table 2). With the six traits included, $74 \%$ of all variation lay along the first principal axis.

The extent to which each trait contributed to the principal axis of variation is indicated by a loading (or weight) assigned to each trait. The directionality of these loadings (Table 2) indicates that the axis can be thought of as a leaf economics spectrum. This spectrum runs from species with potential for quick returns on investments of nutrients and dry mass in leaves to species with a slower potential rate of return. At the quick-return end are species with high leaf nutrient concentrations, high rates of photosynthesis and respiration, short leaf lifetimes and low dry-mass investment per leaf area. At the slow-return end are species with long leaf lifetimes, expensive high-LMA leaf construction, low nutrient concentrations, and low rates of photosynthesis and respiration.

Within growth forms or functional groups the principal axes of variation had the same directionality of trait correlations as for the total data set (Table 2). Similarly, species grouped by major biome type (Fig. 1), or by MAT or MAR classes, yielded the same pattern (data not shown). The concordance of these results is of special significance, indicating a coordination of these key leaf traits that is consistent across major plant functional types, growth forms and biomes. The amount of variation captured by the principal axis in the different species groupings was also similar to that across all species in most cases.

The main exception was among deciduous trees and shrubs where, as expected, there was substantially less variation in LL (5-fold versus 100-fold), and where LL-LMA relationships were partially uncoupled. Still, whereas different growth forms and functional groups were differentiated along the leaf economics spectrum when trait means were considered, the overlap between species groups was large (data not shown). Evergreen trees and shrubs had longer mean LL and higher LMA than deciduous species, but evergreens had much wider ranges for both traits, extending to LLs almost as short as for the shortest-LL deciduous species, and to similarly low LMA. Similarly, on average, shrubs and trees had higher LMA and longer LLs but lower $N_{\text {mass }}, A_{\text {mass }}$ and $\mathrm{Rd}_{\text {mass }}$ than herbs and grasses, yet trees and shrubs spanned almost the entire range of any of these leaf traits. Another example: $\mathrm{N}_{2}$ fixing species had higher mean $N_{\text {mass }}$ than non $\mathrm{N}_{2}$-fixing plants, yet the range of $N_{\text {mass }}$ was larger and extended higher in non $\mathrm{N}_{2}$-fixing species.

\section{Allometries among traits}

Slopes on log-log axes, or 'scaling exponents', indicate the proportionality of pairwise trait relationships. Most slopes were significantly different from +1.0 or -1.0 (Table 1 , above diagonal). In other words, the traits showed allometric relationships rather than scaling in direct proportion with one another ('isometry'). A tenfold increase in $P_{\text {mass }}$ corresponded with a 4.7 -fold increase in $N_{\text {mass }}$ (scaling slope 0.67 ), indicating that $\mathrm{N}: \mathrm{P}$ ratios decline as one moves towards the end of the spectrum that represents quick returns on investments of carbon and nutrients. The stoichiometry between

Table 1 Mass basis of bivariate relationships between the leaf traits

\begin{tabular}{|c|c|c|c|c|c|c|}
\hline & $\log L L$ & $\log$ LMA & $\log A_{\text {mass }}$ & $\log N_{\text {mass }}$ & $\log P_{\text {mass }}$ & $\log R_{\text {mass }}$ \\
\hline $\log \mathrm{LL}$ & & $1.71(1.62,1.82)$ & $-1.38(-1.45,-1.31)$ & $-2.26(-2.39,-2.14)$ & $-1.06(-1.19,-0.94)$ & $-1.67(-1.82,-1.53)$ \\
\hline $\log L M A$ & $0.42(678)$ & & $-0.75(-0.79,-0.72)$ & $-1.28(-1.32,-1.24)$ & $-0.82(-0.86,-0.78)$ & $-0.96(-1.05,-0.88)$ \\
\hline $\log A_{\text {mass }}$ & $0.68(512)$ & $0.50(764)$ & & $1.72(1.63,1.81)$ & $1.03(0.91,1.16)$ & $1.18(1.09,1.27)$ \\
\hline $\log N_{\text {mass }}$ & $0.42(706)$ & $0.57(1958)$ & $0.53(712)$ & & $0.66(0.64,0.69)$ & $0.70(0.64,0.76)$ \\
\hline $\log P_{\text {mass }}$ & 0.24 (207) & 0.55 (739) & $0.16(212)$ & $0.72(745)$ & & $1.04(0.87,1.25)$ \\
\hline $\log R_{\text {mass }}$ & $0.60(217)$ & $0.45(274)$ & 0.59 (259) & $0.55(267)$ & $0.34(78)$ & \\
\hline
\end{tabular}

Standardized major axis slopes with $95 \%$ confidence intervals are given in the upper right section of the matrix $(y$ variable is column $1, x$ variable in row 1$)$. Coefficients of determination $\left(r^{2}\right)$ and sample sizes are given in the lower left section of the matrix. All relationships were highly significant, $P \ll 0.0001$. Further details allowing calculation of predictive regression equations for each pair of leaf traits are given in Supplementary Information. 
Table 2 Principal components analyses of global leaf trait data

\begin{tabular}{|c|c|c|c|c|c|c|c|c|c|c|c|c|c|}
\hline & All species & Trees $^{*}$ & Shrubs & Herbs* & Grasses* & $\mathrm{N}_{2}$-fixers ${ }^{*}$ & $\begin{array}{c}\text { Non } \\
\mathrm{N}_{2} \text {-fixers }\end{array}$ & C3 & $\mathrm{C} 4 \dagger$ & $\begin{array}{c}\text { Broad-leaved } \\
\text { shrubs } \\
\text { and trees }\end{array}$ & $\begin{array}{c}\text { Needle-leaved } \\
\text { shrubs } \\
\text { and trees }\end{array}$ & $\begin{array}{l}\text { Evergreen } \\
\text { shrubs } \\
\text { and trees }\end{array}$ & $\begin{array}{c}\text { Deciduous } \\
\text { shrubs } \\
\text { and trees* }\end{array}$ \\
\hline $\begin{array}{l}\text { Variation explained (\%) } \\
\text { Leaf trait }\end{array}$ & $\begin{array}{c}74.4 \\
\text { Loadings }\end{array}$ & 77.2 & 72.0 & 67.8 & 70.7 & 79.6 & 75.0 & 73.0 & 68.7 & 72.4 & 58.0 & 64.0 & 48.5 \\
\hline LL & -0.85 & -0.90 & -0.83 & -0.73 & -0.86 & -0.86 & -0.84 & -0.88 & & -0.84 & -0.79 & -0.74 & -0.43 \\
\hline LMA & -0.88 & -0.84 & -0.84 & -0.72 & -0.91 & -0.87 & -0.87 & -0.84 & -0.84 & -0.84 & -0.73 & -0.82 & -0.28 \\
\hline$N_{\text {mass }}$ & 0.91 & 0.82 & 0.91 & 0.89 & 0.71 & 0.88 & 0.92 & 0.90 & 0.71 & 0.90 & 0.71 & 0.87 & 0.81 \\
\hline$A_{\text {mass }}$ & 0.86 & 0.91 & 0.82 & 0.88 & 0.79 & 0.96 & 0.86 & 0.88 & 0.87 & 0.83 & 0.82 & 0.76 & 0.84 \\
\hline$R_{\text {mass }}$ & 0.88 & 0.93 & 0.83 & 0.89 & 0.93 & 0.89 & 0.89 & 0.90 & 0.88 & 0.84 & 0.74 & 0.82 & 0.90 \\
\hline$P_{\text {mass }}$ & 0.79 & & 0.87 & & & & 0.80 & 0.72 & & 0.85 & & 0.78 & \\
\hline
\end{tabular}

The principal axis or component explained $74.4 \%$ of variation in the total data set. LL and LMA were negatively correlated with this primary axis of variation while the other traits were positively correlated with it, both in the total data set and in data subsets defined by growth form or functional group. The same directionality of trait loadings and similarly high percentage of variance was explained by the principal axis with species grouped by site temperature, rainfall or altitude, or with sites grouped into major biome type following Fig. 1 (data not shown), demonstrating the broad generality of the coordinated spectrum of leaf economics. All data were $\log _{10}$-transformed before analyses.

${ }^{\star} P_{\text {mass }}$ excluded due to too few data.

$† P_{\text {mass }}$ and LL excluded due to few data. C3, C4 indicate species with $\mathrm{C} 3$ and $\mathrm{C} 4$ photosynthetic pathways, respectively.

leaf $\mathrm{N}$ and $\mathrm{P}$ has begun to attract increasing interest as an index of soil nutrient limitation (taken across sets of co-occurring species) ${ }^{25}$, and also because it relates to plant growth strategies and influences plant-herbivore interactions in food webs ${ }^{26}$.

The slope of the LL-LMA relationship was 1.7 , meaning that tenfold greater dry mass invested per unit leaf area coincided with 50 -fold longer LL. All else being equal, this implies that the measure of light-intercepting leaf area (in $\mathrm{mm}^{2}$ ) $\times$ duration (in months) per gram leaf was greater for high-LMA than for low-LMA species. If this measure translated directly into fitness benefit, this might lead to runaway selection towards ever-increasing LMA and $\mathrm{LL}^{27}$. But continuing ecological success of low-LMA species shows that all else is not equal. On average, a tenfold decrease in LMA, for example, coincided with a 21-fold increase in photosynthetic capacity. Further, low LMA, high $A_{\text {mass }}$ and generally faster turnover of plant parts permit a more flexible response to the spatial patchiness of light and soil resources ${ }^{28}$, as well as conferring advantages via a compound interest effect, whereby carbon fixed earlier can be reinvested in new leaves sooner ${ }^{27,29}$. On the other hand, high $A_{\text {mass }}$ requires high $N_{\text {mass }}$, and the combination of high LMA and high $N_{\text {mass }}$ may increase vulnerability to herbivory as well as increasing energy losses via respiration ${ }^{9}$, which can be detrimental in situations where energy gain is low owing to low resource availability, such as under low light conditions ${ }^{30}$.

\section{Area versus mass basis of expression}

Because $N_{\text {mass }}=N_{\text {area }} / \mathrm{LMA}$, we considered whether the relationship between $N_{\text {mass }}$ and LMA should be thought of as arising from $N_{\text {area }}$ values that do not vary greatly across species, divided through by highly varying LMA. The evidence contradicts this interpretation. First, $N_{\text {area }}$ varied more widely than $\operatorname{did} N_{\text {mass }}$ (35-fold versus 26-fold; data for 1,958 species). Second, the -1.28 slope of the $N_{\text {mass }}$-LMA relationship was significantly steeper (Table 1 ) than the -1.0 slope expected if $N_{\text {area }}$ was independent of LMA.

$N_{\text {area }}$ was indeed correlated with LMA, but positively, and more weakly than were $N_{\text {mass }}$ and LMA ( $r^{2}=0.34$ versus 0.57 ; Table 3$)$. Gradients of leaf $\mathrm{N}$ on a mass versus an area basis hence represent fundamentally different multiple-trait gradients because of their different patterns of covariation with $\mathrm{LMA}^{31}$. The leaf economics spectrum of species from low to high $N_{\text {mass }}$ also constitutes a spectrum of decreasing LMA and LL, and of increasing $A_{\text {mass }}$, $R_{\text {mass }}$ and $P_{\text {mass }}$. But a spectrum of leaf types in terms of $N_{\text {area }}$ would be less informative. A given $N_{\text {area }}$ can result from low $N_{\text {mass }}$ combined with high LMA, high $N_{\text {mass }}$ combined with low LMA, or from combinations in between. In general, low $N_{\text {mass }}$ with high LMA represents a species with long-lived leaves and low $A_{\text {mass }}$, while high $N_{\text {mass }}$ with low LMA represents the opposite. As a result, a wider variety of leaf types may be found at a given $N_{\text {area }}$ than at a given $N_{\text {mass }}{ }^{31-33}$. Here for example, LMA varied approximately 20 -fold at the grand mean of $N_{\text {area }}$ versus tenfold at the grand mean of $N_{\text {mass }}$.

Because of the covariation between leaf $\mathrm{N}$ and LMA, relationships between leaf $\mathrm{N}$ and other traits changed substantially when expressed on an area rather than on a mass basis. As seen previously $^{7-9,31,33}$, relationships between leaf $\mathrm{N}$ and $A_{\text {mass }}$ or dark respiration were weaker when considered on an area basis, as were relationships between leaf $\mathrm{P}$ and other traits (Table 3). By also including LMA in analyses, we can quantify the independent effects of leaf structure and nutrient content on $A_{\text {mass }}$ and dark respiration $^{32,34}$. $A_{\text {mass }}$ increased with increasing $N_{\text {mass }}$ at any given LMA, and decreased with increasing LMA at any given $N_{\text {mass }}$ (partial regression coefficients for LMA and leaf $\mathrm{N}, P<0.001$; regression details in Supplementary Information). Similarly, $A_{\text {area }}$ increased with increasing $N_{\text {area }}$ at any given LMA, and decreased with increasing LMA at any given $N_{\text {area }}$ (Fig. $2 \mathrm{~d}$ and Supplementary Information). That is, both leaf structure and nitrogen concentration affect photosynthetic capacity ${ }^{5,6,8,32}$. The independent LMA effect is most probably due to leaves with high mass per area having longer diffusion paths from stomata to chloroplasts or greater internal shading of lower chloroplasts, limiting the $A_{\text {mass }}$ possible for a given leaf protein content ${ }^{14,15,35}$. Also, less of the $\mathrm{N}$ may be invested in photosynthetic versus non-photosynthetic leaf components in high-LMA species ${ }^{36,37}$. Similarly, $N_{\text {mass }}$ and LMA showed independent effects on $R_{\text {mass }}$ (partial regression coefficients both

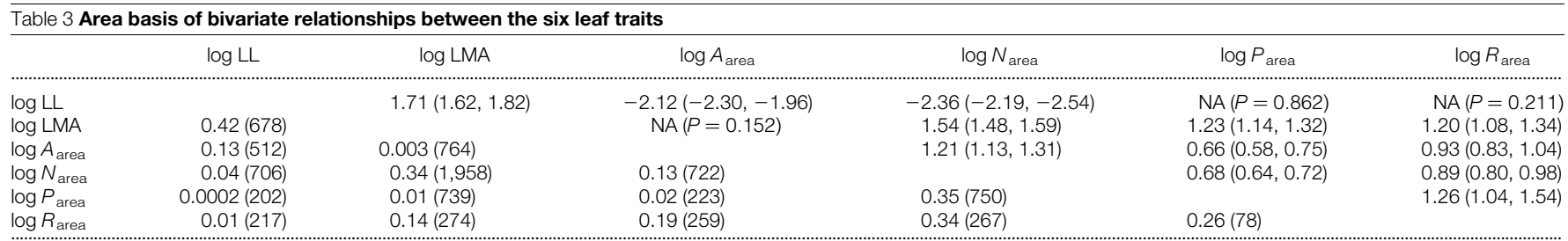

Standardized major axis slopes with $95 \%$ confidence intervals are given in the upper right section of the matrix ( $y$ variable is column $1, x$ variable in row 1$)$. Coefficients of determination $\left(r^{2}\right)$ and sample sizes are given in the lower left section of the matrix. NA, not applicable: in these cases the correlation was clearly non-significant ( $P$ values given in parentheses). While a standardized major axis can still be fitted in such cases, its slope is essentially meaningless. All other relationships were highly significant, $P \ll 0.0001$, with the exception of those between log $P$ area and each of log LMA $(P=0.029)$ and $\log A_{\text {area }}(P=0.034)$. Further details allowing calculation of predictive regression equations for each pair of traits are given in the Supplementary Information. 
$P<0.001$ ), although the physiological basis for an independent LMA effect on $R_{\text {mass }}$ is less clear than for photosynthetic capacity ${ }^{9}$.

Relating to the weaker and somewhat different pattern of areabased trait relationships, the principal axis of a principal components analysis involving LMA, LL, $A_{\text {area }}, R_{\text {area }}, N_{\text {area }}$ and $P_{\text {area }}$ explained a lower proportion of total trait variation than the massbased equivalent and had a different pattern of trait loadings. This principal axis explained $43 \%$ of variation (versus $74 \%$ on a mass basis), and largely reflected a spectrum of increasing $N_{\text {area }}$ (the trait with the strongest trait loading; Supplementary Information). The five other traits showed positive loadings with the principal axis, with these loadings clearly weaker than in the mass-based analysis. About half the residual variation was explained by a second principal axis, which expressed essentially the same trait correlations as the first axis from the mass-based analysis. Together, these first two axes explained $72 \%$ of total trait variation in the area-based data set, marginally less than the first principal axis in the massbased analysis. Area-based analyses for species grouped by growth form, functional type or biome showed patterns broadly concordant with those across all species, though less clearly than for the mass-based analyses (results not shown).

In summary, the coordination among leaf traits appears to be stronger and simpler on a mass basis than an area basis. This is not because area-basis traits are less varied among species. Rather it is because the LMA-LL spectrum is related to mass-based nutrient concentrations and assimilation and respiration rates in a simpler way than on an area basis.

\section{Climate influence on leaf investment}

Plant ecologists have emphasized broad relationships between leaf traits and climate for at least a century. In particular, a general tendency for species inhabiting arid and semi-arid regions to have leathery, high-LMA leaves has been reported ${ }^{4,10,38-40}$. Building highLMA leaves needs more investment per unit leaf area. Construction cost per unit leaf mass varies relatively little between species: leaves with high protein content (typically low-LMA leaves) tend to have low concentrations of other expensive compounds such as lipids or lignin, and high concentrations of cheap constituents such as minerals ${ }^{41}$. Leaf traits associated with high LMA (for example, thick leaf blade; small, thick-walled cells) have been interpreted as adaptations that allow continued leaf function (or at least postpone leaf death) under very dry conditions, at least in evergreen species.

We characterized sites by annual means of temperature, potential evapotranspiration (PET), vapour pressure deficit (VPD) and solar

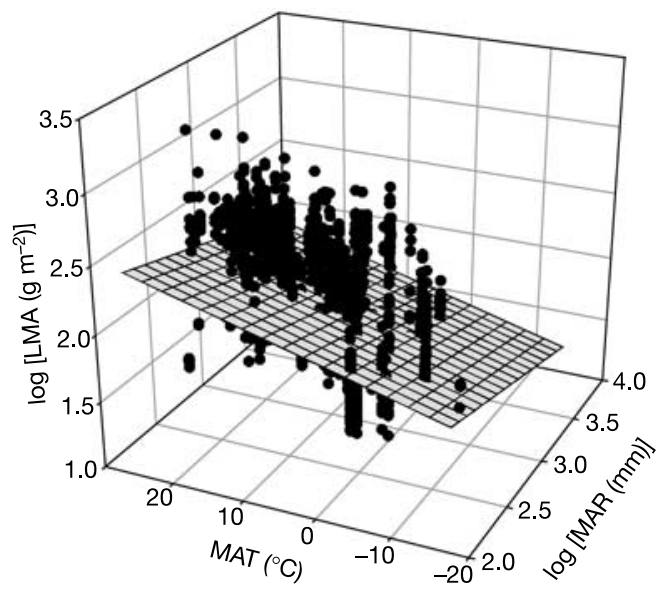

Figure 3 LMA as a function of MAT and MAR at the study sites (data for 2,370 species from 163 sites; rainfall and LMA are $\log _{10}$-scaled). The coefficients for MAT and log rainfall were highly significant in a multiple regression (both $P<0.0001$; further details given in Supplementary Information). irradiance, and MAR. PET, VPD and irradiance were crosscorrelated with rainfall and temperature. Against expectations, LMA showed only a very weak relationship with lower rainfall, considered worldwide $\left(r^{2}=0.002, P=0.032 ; 2,370\right.$ species from 163 sites). LMA was actually more strongly (positively) correlated with MAT $\left(r^{2}=0.10\right)$. Worldwide, precipitation is correlated with temperature, cold high-latitude environments typically having low precipitation (Fig. 1). Once variation in MAT was controlled in a multiple regression, LMA did indeed increase as rainfall decreased (Fig. 3). Similarly, LMA was more strongly (positively) correlated with VPD $\left(r^{2}=0.15\right)$, PET $\left(r^{2}=0.15\right)$ or site irradiance $\left(r^{2}=0.18\right)$ than with MAT or site rainfall alone.

Despite the substantial overlap in leaf traits of evergreen and deciduous species, these species groups varied somewhat in their leaf trait-climate relationships. LMA and rainfall showed a strong negative relationship in evergreen shrubs and trees, whereas in deciduous species they were virtually unrelated $\left(r^{2}=0.22\right.$ versus 0.002). Across all species, LL was positively correlated with PET, VPD, MAT and site irradiance ( $r^{2}$ values ranging from 0.04 to 0.10 ). In deciduous trees and shrubs these relationships were consistently stronger $\left(r^{2}\right.$ values ranged from 0.37 to 0.51$)$. That is, LL of deciduous species was shorter at colder sites where the growing season was shorter. But in evergreen shrubs and trees, LL tended to be longer at colder, lower-humidity sites (for example, MAT versus LL, $r^{2}=0.10$; PET versus LL, $r^{2}=0.18$ ). This is consistent with cold climate vegetation being typically $\mathrm{N}$-limited and demonstrating 'slow-return' strategies ${ }^{42}$.

\section{Trait coordination is largely independent of climate}

A major aim of the Glopnet collaboration was to obtain enough coverage of climate variation to dissect out effects of climate on relationships between leaf economic traits. There were indeed statistically significant effects of climate. Nevertheless, a major finding from this project is that the influence of climate was, in general, quite modest. How can this be, given that traits such as LMA and LL vary systematically with MAR, MAT and other climate indices? The answer seems to have two elements.

First, much of the total leaf economic variation occurs among coexisting species. The proportion of total variation in LL within sites was $57 \%$, the remaining $43 \%$ occurring between sites (variance components analysis). For $R_{\text {mass }}$, the proportion of within-site variation was $67 \%$, for $A_{\text {mass }} 48 \%$, for $N_{\text {mass }} 38 \%$, for LMA $36 \%$,

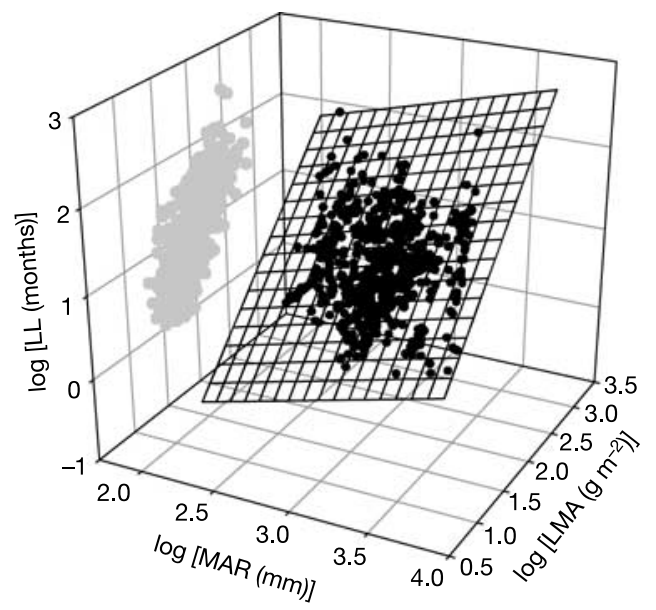

Figure $4 \mathrm{LL}$ as a function of LMA and MAR (all axes are $\log _{10}$-scaled). When viewed in three dimensions, the two-dimensional LL-LMA cloud of points is spread along a sloping surface. The slope of this surface is steeper in the LMA dimension than in the rainfall dimension, reflecting the higher partial regression coefficient for $L M A(1.23$ versus 0.47$)$. Both coefficients were highly significant in a multiple regression $(P<0.0001$; $r^{2}=0.51$; data for 678 species from 51 sites). 
for $P_{\text {mass }} 20 \%$. Similar or higher proportions of within-site variation were seen for area-based traits (40-57\% of total variation). Second, leaf traits tend to vary in concert, with the leaf economics spectrum operating similarly in different biomes. Considered across all species, when single or multiple climate variables were included in regressions of LMA on $N_{\text {mass }}$, of $A_{\text {mass }}$ on $N_{\text {mass }}$, or of LL on $A_{\text {mass }}$, they added a maximum of 0.05 to the $r^{2}$. Similar results were found for most other bivariate trait relationships, as well as for regression models predicting one leaf trait from two or more other leaf traits as well as climate variables $(<15 \%$ explanatory power added).

This is not to say that climate does not exert important influences on trait relationships. With such large sample sizes, these effects were still highly statistically significant. Rather, it is an extension of the fact that so much of the total variation in leaf traits is captured by the primary axis of the leaf economics spectrum. Adding climate variables to regressions involving area-based traits also added little explanatory power, for the most part. Exceptions were cases where the bivariate trait relationship was particularly weak to start with (for example, between $A_{\text {area }}$ and LMA, $R_{\text {area }}$ and LMA, or LL and $A_{\text {area }}$, climate variables added 0.15 to 0.28 to the model $r^{2}$ ).

\section{LL-LMA relationships shift with climate}

The relationship between LMA and LL is important for leaf economics, LMA reflecting the dry-mass cost of deploying new leaf area, and LL representing the duration over which photosynthetic revenue is returned. LL increased with LMA across all species, LMA explaining $42 \%$ of variation in LL (Table 1). This relationship showed quite substantial patterning with climate. At a given LMA, LL was shorter at sites of lower rainfall (Fig. 4), meaning that the duration of return from a unit investment in leaf tissue tends to be shorter in such places. In addition, at sites with harsher climate the gain in LL for a given increase in LMA was less. Significant negative interaction terms in the regression models (all $P<0.001$ ) indicated decreasing steepness for LL-LMA relationships in hotter, less humid (higher VPD or PET) or higher irradiance environments. The patterning of LL-LMA relationships with rainfall that was seen in our global data set was reported previously for evergreen species from four sites in eastern Australia ${ }^{17}$.

Glopnet results serve to confirm and extend the pattern across several hundred more species, from many more vegetation types. The previous comparisons deliberately contrasted sites with similar MAT. Here, by taking data from many more sites, representing most of the major biomes of the earth, we have been able to identify previously undescribed patterning of LL-LMA relationships with respect to climate, that is, the shallower response of LL to LMA with increasing MAT, VPD, PET and site irradiance.

A possible reason why a given LMA is associated with shorter LL in drier environments involves leaf nitrogen. For evergreen species in semi-arid habitats in eastern Australia ${ }^{10}$, the $\mathrm{CO}_{2}$ concentration inside leaves during photosynthesis was lower at a given stomatal conductance to $\mathrm{CO}_{2}\left(g_{\mathrm{CO}_{2}}\right)$ than for evergreen species at higher rainfall sites. That is, they had higher carbon fixation $\left(A_{\text {area }}\right)$ at a given stomatal conductance to water per unit leaf area $\left(g_{\mathrm{H}_{2} \mathrm{O}}\right)$, because $A_{\text {area }}$ is largely the product of $\mathrm{CO}_{2}$ drawdown and $g_{\mathrm{CO}_{2}}$, and $g_{\mathrm{CO}_{2}}$ is directly proportional to $g_{\mathrm{H}_{2} \mathrm{O}}$ (ref. 13). The lower $\mathrm{CO}_{2}$ concentration inside leaves in the species from semi-arid sites was linked with higher $N_{\text {area }}$, but the high $N_{\text {area }}$ corresponded to less robust tissue-a larger proportion of photosynthetic mesophyllresulting in leaves that were less strong in a biomechanical sense at a given LMA and, it was argued, leading to the observed shorter LL at a given $\mathrm{LMA}^{17}$.

We do not yet have leaf toughness information or leaf anatomy widely across our global data set, but $N_{\text {area }}$ did indeed increase with decreasing site rainfall in evergreen trees and shrubs $\left(r^{2}=0.18\right)$, as well as across all species (albeit more weakly; $r^{2}=0.04$ ), $\mathrm{CO}_{2}$ drawdown increased with increasing $N_{\text {area }}$ at a given $g_{\mathrm{H}_{2} \mathrm{O}}$ (see
Supplementary Information), and $A_{\text {area }}$ was higher at a given $g_{\mathrm{H}_{2} \mathrm{O}}$ at lower rainfall sites (see Supplementary Information), indicating that $\mathrm{CO}_{2}$ concentration inside leaves tended to be lower at low rainfall sites (correlation $r=0.44, P<0.0001$ ). Taken together, these trends can be understood as resulting from the simultaneous optimization of nitrogen- and water-use during photosynthesis ${ }^{19,20}$. They suggest that similar mechanisms operate in many of the world's vegetation types, as were seen in the eastern Australian species.

\section{Conclusions}

We now have wide-ranging and convincing evidence that feasible leaf investment strategies are to a great extent arrayed along a single spectrum, with the same patterning of trait correlations seen globally and in species grouped by growth form, biome or climate. Besides leaf economics, many activities such as seed production, root economics and relations with mycorrhizas are undoubtedly important for plant fitness. But, surely, the broad generality of the relationships we describe suggests that natural selection eventually eradicates leaf investment strategies that are not economically competitive. The leaf economics spectrum reflects a mixture of direct and indirect causal relationships between traits.

For example, the linkage of high $A_{\text {mass }}$ with high $N_{\text {mass }}$ is in large part the result of a direct causal relationship ${ }^{8}$. Similarly, long LL requires the robustness and low palatability (including chemical defences) associated with high $\operatorname{LMA}^{17,18}$. More indirectly, high $A_{\text {mass }}$ tends to be associated with short LL because it requires high $N_{\text {mass }}$ and/or low LMA, which increase leaf vulnerability to herbivory and physical hazards, and because high $A_{\text {mass }}$ drives fast growth, rapidly shading older leaves, leading them to senesce once their resources become more valuable when transferred to better-lit newer foliage ${ }^{43}$. The absence of outliers in the trait relationships is particularly striking. Although species vary widely in growth form, life history and niche space occupied, it seems that a mixture of physiological causation and the demands of competitiveness constrain species data points within tightly bounded domains of trait space 6 .

Overall, we found that the effect of climate on leaf trait relationships was modest, although particular trait-pairs showed striking and significant patterns with site climatic properties. Reliable quantification of the global leaf economics spectrum and its relationship to climate should prove valuable in modelling how carbon and nitrogen are tied up and used in plant biomass, and how nutrient fluxes and vegetation boundaries will shift with land-use and climate change. Recent models of vegetation dynamics under global change $e^{44,45}$ do make use of the LMA spectrum previously described in ref. 6 for the purpose of grouping species into plant functional types. Recognition of the leaf economics spectrum strengthens and consolidates our knowledge in this regard. At the same time, it is important to note that the spectrum is continuous, rather than divided into distinct categories either by growth form or by habitat. Formulations of plant functional typologies that represent variation as a continuous spectrum, rather than distinct categories, bear promise for the future.

\section{Methods}

\section{Leaf traits}

Leaf trait data were compiled from both published and unpublished sources. A data set was considered suitable provided it contained data for at least two of the leaf traits for at least four co-occurring species. Highly artificial vegetation types such as forestry plantations and crop fields were not included. Only site-based data sets were used so that we could reasonably attach climate data. The total data set (Supplementary Information)

represented 175 sites and contained 2,548 species-site combinations, consisting of 2,021 species, with 350 occurring at more than one site.

\section{Climate}

Climate data were taken from (1) the sites themselves, where known; (2) the nearest weather stations, with temperature data scaled where necessary by an altitudinal lapse rate of $0.6^{\circ} \mathrm{C}$ per $100 \mathrm{~m}$ (ref. 46 ); (3) a global $0.5 \times 0.5^{\circ}$ data set of MAT, MAR, vapour pressure and irradiance ${ }^{47} ;(4)$ a global $0.5 \times 0.5^{\circ}$ data set of Penman-Monteith PET calculated for 
the period 1987-1988 (ref. 48). MAT and rainfall data from the global data set agreed closely with known or nearby-station data (scaled for altitude where necessary), giving us confidence that the vapour pressure and irradiance data were reliable also. Irradiance data were not adjusted for altitude because increases in cloud cover with elevation tend to offset the increase in radiation that would be observed in clear air, although this may not be true for high-elevation sites in arid regions ${ }^{46,49}$. For high-elevation sites, PET was estimated from a regression equation fitted to all other sites, which considered PET as a function of MAT and annual rainfall $\left(r^{2}=0.71\right)$. Vapour pressure was scaled for high-elevation sites using an empirical formula expressing the exponential decrease of vapour pressure with altitude ${ }^{49}$. Monthly mean VPD was estimated as the difference between the saturation vapour pressure of air (at the monthly mean temperature) and vapour pressure taken from the global data set. Saturation vapour pressure was calculated using the Tetens formula ${ }^{50}$. Climate variables were averaged or summed (rainfall) across all months of the year, and for those months with mean temperature over $4.99^{\circ} \mathrm{C}$, giving an estimate of climate during the growth season. Results using yearly and growth-season climate indices differed little, so we report results relating to yearly climate averages only.

\section{Data transformation and analysis}

For each species at each site, the mean value for each trait was used. Where traits were reported separately for sun leaves and shade leaves, sun-leaf data were used. Similarly, if data were presented separately for recently matured and old leaves, that of the recently matured leaves were chosen. Leaf traits were approximately log-normally distributed across the data set, as were rainfall and VPD. Accordingly, these variables were $\log _{10}$-transformed before analysis. MAT, PET and solar radiation were left untransformed because their distribution across sites was approximately normal.

Standardized major axis slopes ${ }^{24}$ with $95 \%$ confidence intervals were fitted to bivariate trait relationships because our aim was to describe the best-fit lines or central axes of these 'scaling' relationships. Ordinary multiple regression was used for analyses exploring the additional predictive power of climate variables on leaf trait relationships. Regressions were first run including interaction terms between climate variables and leaf traits; where the interaction was non-significant $(P<0.05)$, we re-ran models with main effects only. In several cases, principal components analyses run on data subsets defined by growth form or plant functional type had to be re-run with one or more leaf traits removed, owing to insufficient data. These cases are indicated in Table 2. Variance component analyses were based on the decomposition of analysis of variance (ANOVA) type I sums of squares. Principal components analyses, variance components and regression analyses were run in SPSS for Windows version 11.01

Received 15 July 2003; accepted 10 February 2004; doi:10.1038/nature02403.

1. Bloom, A. J., Chapin, F. S. \& Mooney, H. A. Resource limitation in plants-an economic analogy. Annu. Rev. Ecol. Syst. 16, 363-392 (1985).

2. Orians, G. H. \& Solbrig, O. T. A cost-income model of leaves and roots with special reference to arid and semiarid area. Am. Nat. 111, 677-690 (1977).

3. Givnish, T. J. (ed.) On the Economy of Plant Form and Function (Cambridge Univ. Press, Cambridge/ New York, 1986).

4. Niinemets, U. Global-scale climatic controls of leaf dry mass per area, density, and thickness in trees and shrubs. Ecology 82, 453-469 (2001).

5. Niinemets, U. Components of leaf dry mass per area-thickness and density-alter leaf photosynthetic capacity in reverse directions in woody plants. New Phytol. 144, 35-47 (1999).

6. Reich, P. B., Walters, M. B. \& Ellsworth, D. S. From tropics to tundra: global convergence in plant functioning. Proc. Natl Acad. Sci. USA 94, 13730-13734 (1997).

7. Reich, P. B. et al. Generality of leaf trait relationships: a test across six biomes. Ecology 80, 1955-1969 (1999).

8. Field, C. \& Mooney, H. A. in On the Economy of Plant Form and Function (ed. Givnish, T. J.) 25-55 (Cambridge Univ. Press, Cambridge, 1986).

9. Reich, P. B. et al. Relationships of leaf dark respiration to leaf nitrogen, specific leaf area and leaf lifespan-a test across biomes and functional groups. Oecologia 114, 471-482 (1998).

10. Wright, I. J., Reich, P. B. \& Westoby, M. Strategy-shifts in leaf physiology, structure and nutrient content between species of high and low rainfall, and high and low nutrient habitats. Funct. Ecol. 15, 423-434 (2001).

11. Grime, J. P. et al. Integrated screening validates primary axes of specialisation in plants. Oikos 79, 259-281 (1997).

12. Whittaker, R. Communities and Ecosystems 2nd edn, 167 (MacMillan, New York, 1975).

13. Lambers, H., Chapin, F. S. \& Pons, T. L. Plant Physiological Ecology (Springer, New York, 1998).

14. Parkhurst, D. F. Diffusion of $\mathrm{CO}_{2}$ and other gases inside leaves. New Phytol. 126, 449-479 (1994).

15. Evans, J. R. \& Loreto, F. in Photosynthesis: Physiology and Metabolism (eds Leegood, R. C., Sharkey, T. D. \& von Caemmerer, S.) 321-351 (Kluwer Academic, Dordrecht, 2000).

16. Cannell, M. G. R. \& Thornley, J. H. M. Modelling the components of plant respiration: Some guiding principles. Ann. Bot. 85, 45-54 (2000).

17. Wright, I. J. \& Westoby, M. Leaves at low versus high rainfall: coordination of structure, lifespan and physiology. New Phytol. 155, 403-416 (2002).

18. Coley, P. D. Herbivory and defensive characteristics of tree species in a lowland tropical forest. Ecol. Monogr. 53, 209-233 (1983).

19. Wright, I. J., Reich, P. B. \& Westoby, M. Least-cost input mixtures of water and nitrogen for photosynthesis. Am. Nat. 161, 98-111 (2003).

20. Farquhar, G. D., Buckley, T. N. \& Miller, J. M. Optimal stomatal control in relation to leaf area and nitrogen content. Silva Fennica 36, 625-637 (2002).
21. Reich, P. B., Walters, M. B. \& Ellsworth, D. S. Leaf life-span in relation to leaf, plant, and stand characteristics among diverse ecosystems. Ecol. Monogr. 62, 365-392 (1992).

22. Lambers, H. \& Poorter, H. Inherent variation in growth rate between higher plants: a search for ecological causes and consequences. Adv. Ecol. Res. 23, 187-261 (1992).

23. Wright, I. J. \& Westoby, M. Nutrient concentration, resorption and lifespan: leaf traits of Australian sclerophyll species. Funct. Ecol. 17, 10-19 (2003).

24. Sokal, R. R. \& Rohlf, F. J. Biometry: the Principles and Practice of Statistics in Biological Research (W. H. Freeman, New York, 1995).

25. Koerselman, W. \& Meuleman, A. F. M. The vegetation N/P ratio-a new tool to detect the nature of nutrient limitation. J. Appl. Ecol. 33, 1441-1450 (1996).

26. Sterner, R. W. \& Elser, J. J. Ecological Stoichiometry. The Biology of Elements from Molecules to the Biosphere (Princeton Univ. Press, Princeton/Oxford, 2002)

27. Westoby, M., Warton, D. \& Reich, P. B. The time value of leaf area. Am. Nat. 155, 649-656 (2000).

28. Grime, J. P. in Exploitation of Environmental Heterogeneity in Plants (eds Caldwell, M. M. \& Pearcy, R. W.) 1-18 (Academic, San Diego, 1994).

29. Harper, J. L. The value of a leaf. Oecologia 80, 53-58 (1989).

30. Walters, M. B. \& Reich, P. B. Seed size, nitrogen supply, and growth rate affect tree seedling survival in deep shade. Ecology 81, 1887-1901 (2000).

31. Reich, P. B. \& Walters, M. B. Photosynthesis-nitrogen relations in Amazonian tree species. 2. Variation in nitrogen vis-a-vis specific leaf area influences mass-based and area-based expressions. Oecologia 97, 73-81 (1994).

32. Reich, P. B., Ellsworth, D. S. \& Walters, M. B. Leaf structure (specific leaf area) modulates photosynthesis-nitrogen relations: evidence from within and across species and functional groups. Funct. Ecol. 12, 948-958 (1998).

33. Schulze, E.-D., Kelliher, F. M., Körner, C., Lloyd, J. \& Leuning, R. Relationships among maximum stomatal conductance, ecosystem surface conductance, carbon assimilation rate, and plant nitrogen nutrition: a global scaling exercise. Аnпи. Rev. Ecol. Syst. 25, 629-660 (1994).

34. Peterson, A. G. CMEAL participants. Reconciling the apparent difference between mass- and areabased expressions of the photosynthesis-nitrogen relationship. Oecologia 118, 114-150 (1999).

35. Green, D. S. \& Kruger, E. L. Light-mediated constraints on leaf function correlate with leaf structure among deciduous and evergreen tree species. Tree Physiol. 21, 1341-1346 (2001).

36. Poorter, H. \& Evans, J. R. Photosynthetic nitrogen-use efficiency of species that differ inherently in specific leaf area. Oecologia 116, 26-37 (1998).

37. Hikosaka, K., Hanba, Y. T., Hirose, T. \& Terashima, I. Photosynthetic nitrogen-use efficiency in leaves of woody and herbaceous species. Funct. Ecol. 12, 896-905 (1998)

38. Maximov, N. A. The Plant in Relation to Water. A Study of the Physiological Basis of Drought Resistance (Allen \& Unwin, London, 1929).

39. Schulze, E.-D. et al. Carbon and nitrogen isotope discrimination and nitrogen nutrition of trees along a rainfall gradient in northern Australia. Aust. J. Plant Physiol. 25, 413-425 (1998).

40. Fonseca, C. R., Overton, J. M., Collins, B. \& Westoby, M. Shifts in trait combinations along rainfall and phosphorus gradients. J. Ecol. 88, 964-977 (2000).

41. Villar, R. \& Merino, J. Comparison of leaf construction costs in woody species with differing leaf lifespans in contrasting ecosystems. New Phytol. 151, 213-226 (2001).

42. Oleksyn, J., Reich, P. B., Zytkowiak, R., Karolewski, P. \& Tjoelker, M. G. Nutrient conservation increases with latitude of origin in European Pinus sylvestris populations. Oecologia 136, 220-235 (2003)

43. Ackerly, D. D. \& Bazzaz, F. A. Leaf dynamics, self-shading and carbon gain in seedlings of a tropical pioneer tree. Oecologia 101, 289-298 (1995).

44. Bonan, G. B., Levis, S., Kergoat, L. \& Oleson, K. W. Landscapes as patches of plant functional types: an integrating concept for climate and ecosystem models. Glob. Biogeochem. Cycles 16, doi:10.1029/ 2000GB001360 (2002)

45. Moorcroft, P. R., Hurtt, G. C. \& Pacala, S. W. A method for scaling vegetation dynamics: The ecosystem demography model (ED). Ecol. Monogr. 71, 557-585 (2001).

46. Körner, C. Alpine Plant Life: Functional Plant Ecology of High Mountain Ecosystems Ch. 3 (Springer, Berlin, 1999).

47. New, M., Hulme, M. \& Jones, P. Representing twentieth-century space-time climate variability. Part I: Development of a 1961-90 mean monthly terrestrial climatology. J. Clim. 12, 829-856 (1999).

48. Choudhury, B. J. Global pattern of potential evaporation calculated from the Penman-Monteith equation using satellite and assimilated data. Remote Sens. Environ. 61, 64-81 (1997).

49. Barry, R. G. Mountain Weather and Climate 24-29 (Methuen, London/New York, 1981).

50. Campbell, G. S. \& Norman, J. M. An Introduction to Environmental Biophysics (Springer, New York, 1998).

Supplementary Information accompanies the paper on www.nature.com/nature.

Acknowledgements All authors contributed (mostly unpublished) data and intellectual input to the project. The first three authors took the lead in the organization, analysis and writing-up of this work, and contributed $8 \%$ of the data, with 223 species from 11 sites. We also thank the many other researchers who provided additional information about their study sites and published data.

Competing interests statement The authors declare that they have no competing financial interests.

Correspondence and requests for materials should be addressed to I.W. (iwright@rna.bio.mq.edu.au). 